\title{
Bone cement adhesion on ceramic surfaces-Surface activation of retention surfaces of knee endoprostheses by atmospheric pressure plasma vs. thermal surface treatment
}

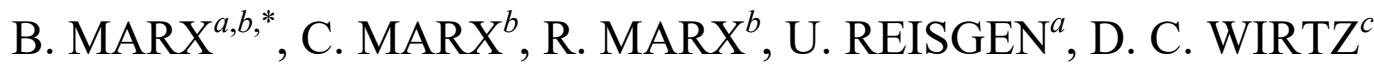 \\ ${ }^{a}$ ISF Welding and Joining Institute RWTH Aachen University, Pontstrasse 49, 52062 Aachen, Germany \\ ${ }^{b}$ CC\&A Medical Components Ltd., Center for Biomedical Engineering, Pauwelsstrasse 17, 52074 Aachen, Germany \\ ${ }^{c}$ Orthopaedics and Traumatology Clinic University Hospital Bonn, Sigmund-Freud-Strasse 25, 53127 Bonn, \\ Germany
}

Received: January 15, 2016; Accepted: February 16, 2016

(C) The Author(s) 2016. This article is published with open access at Springerlink.com

\begin{abstract}
CoCrMo alloys are contraindicated for allergy sufferers. For these patients, uncemented and cemented prostheses made of titanium alloy are indicated. Knee prostheses machined from that alloy, however, may have poor tribological behavior. Therefore, for allergy sufferers, knee replacements in form of cemented high-strength oxide ceramic prostheses which reveal excellent tribological behavior are suitable. In addition, the rate of particle induced aseptic loosening may be reduced. For adhesion of bone cement, the smooth ceramic surface, however, exposes inefficient mechanical retention spots as compared with a textured metal surface. Undercuts generated by corundum blasting, which in the short and intermediate term are highly efficient on a CoCrMo surface, are not appropriate on a ceramic surface due to the brittleness of ceramics. The corresponding textures may initiate cracks which will weaken the strength of a ceramic prosthesis. Due to the lack of textures, mechanical retention is poor or even not existent. Micromotions are facilitated and early aseptic loosening is predictable. Instead silicoating of the ceramic surface will allow specific adhesion and result in better hydrolytic stability of bonding, thereby preventing early aseptic loosening. Silicoating, however, presupposes a clean and chemically active surface which may be achieved by atmospheric plasma or thermal surface treatment. In order to evaluate the effectiveness of silicoating, the bond strengths of atmospheric plasma versus thermal surface treated and silicoated ZPTA (zirconia platelets toughened alumina) surfaces were compared with "as-fired" surfaces by utilizing TiAlV probes (diameter: $6 \mathrm{~mm}$ ) for traction-adhesive strength test. After preparing samples for traction-adhesive strength test (sequence: ceramic substrate, silicate layer and penetrated silane, protective lacquer (PolyMA), bone cement, TiAlV probe), they were aged up to 150 days at $37{ }^{\circ} \mathrm{C}$ in Ringer's solution. The bond strengths observed for all aging intervals were well above $20 \mathrm{MPa}$ and much higher and more hydrolytic stable for silicoated compared with "as-fired" ZPTA samples. Silicoating may be effective for achieving high initial bond strength of bone cement on surfaces of oxide ceramics and is also suitable to stabilize bond strengths in the long term under hydrolytic conditions as present in the human body. Activation by atmospheric plasma or thermal surface treatment seems to be effective prior to silicoating. Due to the proposed silicate layer migration, micromotions and debonding should be widely reduced or even eliminated.
\end{abstract}

Keywords: total knee replacement out of oxide ceramics; aseptic loosening; allergenic potential;

\footnotetext{
* Corresponding author.

E-mail: marx@isf.rwth-aachen.de
} 
atmospheric plasma treatment; silicoating; hydrolytic stability

\section{Introduction}

CoCrMo steels are standard alloys for cemented hip and knee endoprostheses. Titanium and its alloys are standard materials for uncemented hip and knee endoprostheses. Advanced layering methods, however, offer the possibility to make available titanium and its alloys, in particular $\mathrm{TiAl}_{6} \mathrm{~V}_{4}$ alloy, for cemented endoprostheses as well [1]. High-strength ceramic materials, in particular dispersion ceramics based on aluminium and zirconium oxide (ZPTA (zirconia platelets toughened alumina) or ATZ (alumina toughened zirconia), respectively) are utilized for ball heads of femoral shafts and acetabulum inlays, for artificial knee prostheses; however, ceramics are utilized only rarely up to now. Clinical experiences with ceramic materials are available, however, for uncemented artificial knees out of $\mathrm{Al}_{2} \mathrm{O}_{3}$ from the Asian region [2,3].

Aseptic loosening due to wear of the artificial inlay machined out of UHMWPE (ultra high molecular weight polyethylene) is one important reason for revision surgery in the field of knee endoprosthetics. In simplified terms the pathogenetic sequence may be described as follows. Wear particles due to interaction between the surface of the prosthesis and the inlay distribute into the synovia fluid, and via this fluid penetrate the interface between implant and adjacent bone. Macrophages are activated which differentiate as osteoclasts dissolving and absorbing bone. The gap between implant and adjacent bone widens even more accelerating the dissolving and absorption process. This vicious circle leads to destabilization and finally to the loss of the implant [4]. Note that there are materials which as a bulk are biocompatible, and their wear particles, however, have not this property inevitably [5].

Therefore it is mandatory to minimize the quantity of wear particles by utilizing tribological pairings with minimal wear, i.e., pairings with favorable tribological properties. The tribological properties of material pairings depend on the existence of an effective lubricating film between the sliding partners. The more effective lubricating film is, the better the lubricating film wets both the surfaces of the sliding partners. The surface tension (surface energy $\gamma$ ) of the inlay material
$\mathrm{PE}$ is $31 \mathrm{mN} / \mathrm{m}$, of $\mathrm{Al}_{2} \mathrm{O}_{3} 31 \mathrm{mN} / \mathrm{m}$ as well, and of titanium it is $47 \mathrm{mN} / \mathrm{m}$ [6]; CoCrMo alloys and ZPTA ceramics show the values $\gamma=39 \mathrm{mN} / \mathrm{m}$ and $\gamma=44 \mathrm{mN} / \mathrm{m}$, respectively [7]. The main component of the synovial fluid is water. Its surface tension is $\gamma=73 \mathrm{mN} / \mathrm{m}$. Therefore, all surfaces with $\gamma<73 \mathrm{mN} / \mathrm{m}$ are hydrophobic, however varying in grading. Hydrophilic surfaces have a surface tension of at least $73 \mathrm{mN} / \mathrm{m}$. Approximating the value of $73 \mathrm{mN} / \mathrm{m}$ from below has the meaning that the surfaces become less and less hydrophobic.

Therefore, the present ceramic materials have hydrophobic behavior but the degree of hydrophobicity is lower than that of CoCrMo alloys, for instance [8]. As a consequence, compared to CoCrMo alloys, these ceramics are better wetted by the synovial liquid, meaning that better lubrication exists between the PE inlay and the sliding surfaces of the prostheses.

However, the wetting behavior of ceramics is not completely describable in terms of "surface energy". Contrary to a metal due to its ionic chemical bonding characteristics via hydrogen bridge linkage, a thin watery layer (thickness: one monolayer) is built on the surface in the presence of water molecules. As a consequence, the ceramic surface in effect becomes hydrophilic despite $\gamma<73 \mathrm{mN} / \mathrm{m}$. This watery layer enhances the lubrication effect of the synovial fluid. Less friction in the gap between PE inlay and ceramic surface follows [9].

Considering the tribological pairing PE inlay on the one side and ceramics or metal on the other side, ceramics appear to have the more favorable properties. It is to be anticipated that prostheses composed of ceramics should reduce wear debris and hence the potential risk of particle disease accompanied by local osteolysis resulting in aseptic loosening of the implant. Moreover, the risk of allergic reaction is reduced when the rate of wear debris of the prosthesis is reduced.

Unfortunately only few actual in vivo studies concerning the rate of wear debris of ceramicsUHMWPE vs. metal-UHMWPE pairings are known. As a result of a 20-year follow up study, the rate of wear debris of PE liners paired with femoral heads of hip joint endoprostheses (80 patients, 93 hips). Ihle et al. [10] reported a significant lower wear rate for the ceramics-PE pairing as compared with the CoCrMo- 
PE pairing $(0.107 \mathrm{~mm} / \mathrm{a}$ vs. $0.190 \mathrm{~mm} / \mathrm{a})$.

On one hand reducing the detrimental consequences of particle decease by utilizing ceramic materials with $\mathrm{PE}$ as a tribological pairing means on the other hand that it becomes mandatory to reduce other reasons of prosthesis failure namely aseptic loosening in the boundary between endoprosthesis and bone cement due to loss of adhesion. Loosening also appears in the interface of bone/bone cement; investigations on metallic tibia components, however, reveal that loosening predominantly happens between implant and bone cement. This was recently demonstrated by de Uhlenbrock et al. [11] in a post mortem study. In 70\% of all investigated cases, failure transpired in that interface.

For effective cement adhesion, cemented metallic knee endoprostheses inevitably require a rough metal surface having micro mechanical retentions. Therefore, the surface must be sandblasted with corundum of suitable particle size hence exposing sharp-edged textures with their margins bulged. Blasting the surface means not only roughening but also chemically activating it. Moreover, the effective surface becomes larger. The contact angle for wetting becomes smaller indicating better wettability. However note that the bonding between cement and metal remains mechanical in nature, and therefore it is subject to be undermined by water molecules weakening the retention between cement and surface of the prosthesis from year to year inevitably.

The Exeter cemented hip prosthesis has a special position. Contrary to all other prostheses, its surface is smooth without any textures. Its retention mechanism is based on intended wedge action. Because of its smooth surface, the shaft caves and caulks in.

Ceramics are very hard as compared with metals. Therefore, roughening the surface by blasting is difficult. Coarse-grained corundum blasted with high velocity onto the surface is needed to achieve any roughening effect. However, at the same time, this bears the risk of weakening the ceramic prosthesis to an intolerable degree since the blasting process is accompanied by implanting mechanical defects into the surface and hence causing local stress concentrations. Local stress concentrations may be starting points for flaws and cracks. Their consecutive growth can destroy the prosthesis [12]. Therefore, advanced methods of cleaning the surface from physisorbed artefacts are needed, especially from the inevitable monomolecular layer of water [13]. At the same time, the surface will be activated for larger surface energy and hence for better wetting.

Successful physical vapor process (PVD) layering with silicate requires a surface conditioned in a manner as described above. In conjunction with a suitable silane coupling agent, the bond strength to bone cement will be significantly increased and, moreover, in the presence of moisture against the detrimental attack of water molecules stabilized [14]. The combination of a silicate/silane layer between surface and bone cement results in "specific adhesion" in contrast to retention which is due to interlocking, therefore solely mechanical in nature. Retention due to interlocking is prone to hydrolic degradation in contrast to retention which is due to specific adhesion based on a silicate/silane layer [14]. Rough blasting which can be detrimental for the mechanical stability of the prosthesis becomes unnecessary. Micromechanical retention is replaced by specific adhesion.

Specific chemical adhesion occurs when the surface atoms of two separate surfaces form ionic, covalent, or hydrogen bonds. The engineering principle behind chemical adhesion in this sense is fairly straightforward: if surface molecules can bond, then the surfaces will be bonded together by a network of these bonds. These ionic and covalent forces are effective over only very small distance-lesser than a nanometer. This means that surfaces with the potential for chemical bonding need to be brought very close together [15], i.e., they must be clean.

There are two common methods of cleaning the surface from physisorbed contaminations: plasma surface and thermal surface treatment. In order to compare the effectiveness of both desorbing methods, the ceramic surface after firing and machining is firstly cleaned by washing and consecutively plasma or thermally treated. Plasma treatment is effected by argon gas at atmospheric pressure. Energizing the argon gas by a microwave generator subjecting it to a strong magnetic field means that the atoms become ionized converting them to a gas cloud of ions and electrons. This cloud has an impact analogous to blasting and therefore it is also called "micro blasting" with corundum grains replaced by ions and electrons removing hydrocarbon and water molecules. The heat input is so low that the surface temperature only rises by some degrees.

Thermal treatment has analogous effects. It is done in a furnace with ceramic walls at $450{ }^{\circ} \mathrm{C}$ for about $20 \mathrm{~min}$. Hydrocarbon, water molecules, and other 
contaminations will be effectively desorbed [16]. However, the necessity to omit certain areas of a prosthesis from silicoating by masking those areas can cause that desorption by heating is unsuitable because the masking is sensitive to heat. Then plasma treatment is the method of choice.

A silicate layer on the ceramic surface combined with a silane bonding agent can ensure the bonding of bone cement to that surface also in the case of knee prostheses implanted in a surrounding which is wet because that layering ensures stability against hydrolytic detoriation under wet conditions [17-19]. Note that bone cement is tight against water liquid but not against water molecules which will diffuse through the body of bone cement because like all other plastics bone cement is permeable. The diffusion stops at the ceramic boundary; the up to here separated "gaseous" molecules recombine into a water layer in the boundary.

In the present context, the silicate is applied in a PVD ("silicoating"). Because of the time delay between layering and implantation, the final conservation of the silicate/silane layer with a PolyMA coat is mandatory. This coat consists of several methacrylates and is therefore called "PolyMA". The utilized silane must be chemically compatible with it: methacryloxy-propyltrimethoxy-silane (Silane A174). Thereafter $\mathrm{Si}\left(\mathrm{OCH}_{3}\right)_{3}$ groups are present on the surface which are hydrolysable. In presence of water (refer to above), silanol groups emerge reacting with the $\mathrm{SiO}_{x}$ to siloxan groups $[13,14]$. The methacrylate group existing at the other end of the silane molecule reacts with the PolyMA.

Cementing the prosthesis into the patient's knee or hip means that the bone cement "adhesive" comes in contact with the PolyMA layer, and hence the MA-monomers of the cement and of the PolyMA mutually interdiffuse via the interjacent boundary (IPN (interpenetrating polymer network) structure [20,21]; thickness: about $2 \mu \mathrm{m})$. This specific adhesion based on physical/chemical interactions with the ceramic surface amplifies and stabilizes the classical adhesion based on mechanical retention if ever present. A bonding of high strength results, which is stable against hydrolytic attack from the body liquid in particular from its watery components $[13,17]$.

Finally it should be noticed that adhesive techniques exclusively based on mechanical retention are not appropriate to the state of the art of present engineering techniques. Bonding solely based on mechanical retention is in the intermediate term hydrolytically instable [22]. Mechanical retention may be appropriate in dry surroundings; bonding in the human body, however, is subjected to wet and warm environment conditions.

\section{Materials and methods}

Substrate for the present bond strength study was ZPTA ceramics. The circular samples had a diameter of $20 \mathrm{~mm}$ and a thickness of $2 \mathrm{~mm}$. After firing, they were washed and providently degreased by isopropyl alcohol in order to definitively exclude any contamination by fat, oil, or traces due to, e.g., skin contact.

Prior to the PVD silicoating process, the samples were treated by atmospheric plasma in order to desorb monomolecular water layers or other adsorbances chemisorbed or physisorbed onto the ceramic surface. Alternatively the samples were thermally treated in a ceramic furnace. Both treatments mean that the surface becomes highly activated for the sorption of the PVD layer and the consecutively applied silane coupling agent. For plasma treatment, the plasma jet was circumducted in a distance of a few millimeters above the surface of the sample to be layered. Thereby the plasma cloud emanating from the jet treats and cleans the surface. Erroneously touching the ceramic surface with the jet must be avoided by all means because abraded traces of metal would be transferred to the ceramic surface which normally are unremovable.

Baking out the surface was conducted at a temperature of $450{ }^{\circ} \mathrm{C}$ for $10 \mathrm{~min}$. Afterwards the samples were allowed to cool down to room temperature before further treatment steps were started.

After conditioning the surface (plasma vs. heat treatment), it was layered in a PVD system (self built apparatus $[23,24])$ at high vacuum $\left(p \approx 10^{-5} \mathrm{mbar}\right)$. The temperature of the source for evaporating the granules silicon monoxide (Balzers Materials, Principality of Liechtenstein) was stabilized at $1070{ }^{\circ} \mathrm{C}$. The vaporized $\mathrm{SiO}$ condensed from the gas phase onto the substrate surface as $\mathrm{SiO}_{x}$ (typical layer thickness: about $150 \mathrm{~nm}$; $1 \leqslant x \leqslant 2$ ). The source has been manufactured from tantalum/niobium sheets (Testbourne Ltd, Basingstoke, $\mathrm{UK})$. The evaporated $\mathrm{SiO}$ particles followed a path through a series of baffles and emanated out of the exhaust chimney. The evaporated particle cloud condensed onto the surface to be layered as a thin film (thickness: about $120 \mathrm{~nm}$ ). The thickness was measured with the help of interferometric technique 
(NanoCalc2000, OceanOptics GmbH, Ostfildern, Germany).

Next the silane coupling agent solved in alcohol (Espe Sil, 3M ESPE, Seefeld, Germany) was applied. After allowing time for the evaporation of the alcoholic solvent, the layer system was covered by a transparent PolyMA (a mixture of several MAs) protective coat. That coat was cured under UV light at a vacuum of about $p=10^{-1} \mathrm{mbar}$ for $10 \mathrm{~min}$.

For measurement of the bond strength of the silicate/silane/PolyMA layer/cement sequence to the ceramic surface, probes machined out of $\mathrm{TiAl}_{6} \mathrm{~V}_{4}$ alloy (M4 thread, diameter: $6 \mathrm{~mm}$, refer to Fig. 1) were cemented (cement Refobacin-Palacos (Merck Biomaterial, Darmstadt, Germany)) onto the surface of the layer sequence. The probes were conditioned in such a manner $\left(\right.$ Rocatec $^{\circledR}$ treatment 3M ESPE, Seefeld, Germany) that the bond strength between the cement and the $\mathrm{TiAl}_{6} \mathrm{~V}_{4}$ surface was $35 \mathrm{MPa}$ at least $(32 \mathrm{MPa}$ at least after exposure to physiologic saline solution at $37{ }^{\circ} \mathrm{C}$ for 150 days).

The test specimens assembled from ceramic discs and probes were tested for their traction-adhesive strength. To avoid lateral forces as far as possible the testing machine was equipped with two cardan joints one above the test specimen and one below it. Those cardan joints ensure a uniaxial tensile force directed perpendicular to the ceramic disc evenly distributed over the entire cross section and free of momenta. The ceramic disc was inserted into a jig shaped like a double $\mathrm{U}$ (refer to Fig. 2 in Ref. [25]). The probe was screwed into a jig with the M4 thread. The jerk free forward

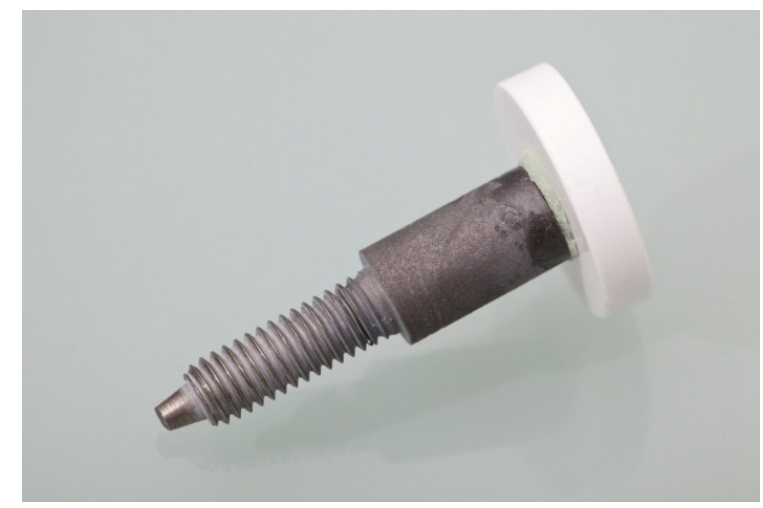

Fig. 1 Traction-adhesive strength test assembly with TiAlV probe (left side) cemented onto a ZPTA disc. For bonding between probe and disc, there is a thin layer of bone cement $\left(\right.$ Palacos $^{\circledR}$, about $0.2 \mathrm{~mm}$ thick). The dark shading of the surface in the cylindrical area of the probe near the cement layer (opposite to the thread) is part of the protecting PolyMA coating unintendedly in excess applied to the front side of the probe. speed was $1 \mathrm{~mm} / \mathrm{min}$ until failure.

The force in Newton at failure divided by the cross section area of the probes $\left(28.3 \mathrm{~mm}^{2}\right)$ corresponds to the bond strength in MPa $\left(\mathrm{N} / \mathrm{mm}^{2}\right)$. This value reflects the adhesion strength of the bone cement to the ceramic surface.

As part of the present investigation, the samples were aged at $37{ }^{\circ} \mathrm{C}$ in physiological saline solution for up to 150 days. The signification was to evaluate the stability of bond strength under conditions reminiscent to those present in the human body.

Moreover, the consequence of omission of either plasma or heat treatment was investigated, and it was evaluated how much time elapses (hours, days) until desorbed surface contaminants are resorbed. The meaning of the latter investigation was to answer the question about the maximum time span to be observed between plasma/heat treatment and silicate layering process without loss of bond strength.

\section{Results}

Figure 2 shows the initial bond strengths (heat treatment vs. plasma treatment) without aging and the bond strengths after aging. Figure 3 compares the bond strengths of PVD layered samples without treatment (column at the utter left) with the bond strengths of samples silicate layered immediately after treatment and of treated samples before silicoating for the time intervals specified in the caption of the abscissa exposed to laboratory environment. Also influence of storage under vacuum conditions ( $1 \mathrm{~d}$ ) was investigated.

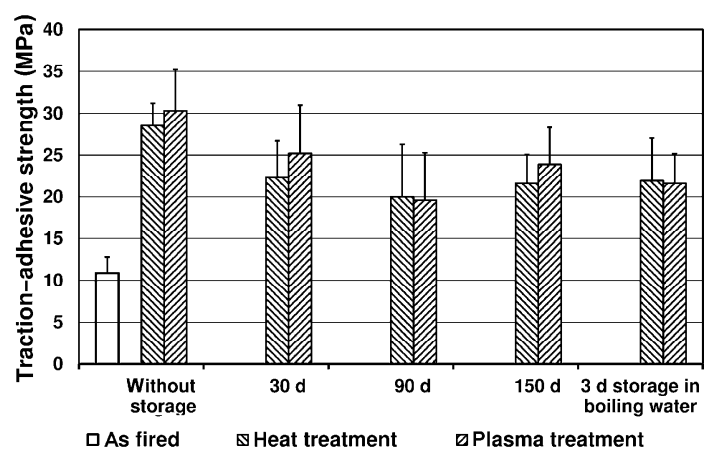

Fig. 2 Bond strengths of bone cement to ZPTA disc. Left column (10.9 MPa) ZPTA disc "as-fired", degreased by treatment with isopropyl alcohol. Probes cemented onto the untreated disc surface. All other columns: ZPTA disc "heat treated" or "plasma treated". PVD layered, silane, and PolyMA application. Aging in Ringer's solution up to 150 days. Palacos ${ }^{\circledR} \mathrm{R}$ cement. 


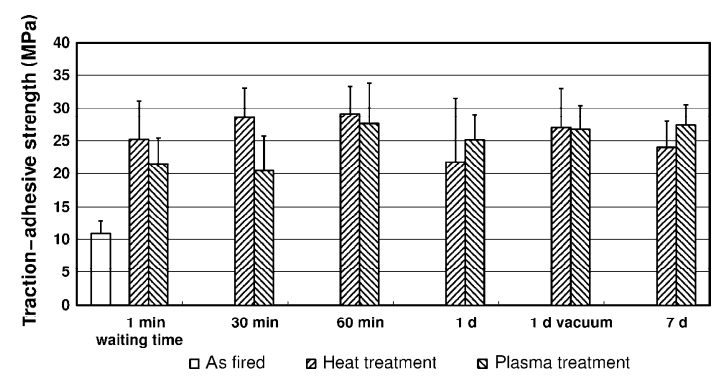

Fig. 3 Bond strengths of bone cement to ZPTA disc. Left column (10.9 MPa) ZPTA disc "as fired", degreased by treatment with isopropyl alcohol. All other columns: ZPTA disc "heat treated" or "plasma treated". For estimation of resorption rates: PVD layering (silicoating), silane, and PolyMA application after different time delays as noted in caption of $x$ axis. After time delays as noted in caption of $x$ axis, TiAlV probes were cemented onto the discs. Time delay in minutes ( $\mathrm{min}$ ) and days (d) for estimation in which time resorption of constituents of lab air takes place potentially interfering with bonding. "Vacuum": $p \approx 10^{-1}$ mbar. Palacos ${ }^{\mathbb{R}} \mathrm{R}$ cement.

\section{Discussion}

Normally the retention surfaces of prostheses are roughened by blasting with the aim to enable mechanical retention to bone cement due to positive interlocking to the surface $[18,26]$. Prostheses machined out of ceramics must not be roughened since notches and indentations can be sources of flaws and cracks inducing decrease in strength under tension forces due to crack propagation [12]. Figure 2 demonstrates that roughening becomes unnecessary when instead of blasting the surface is treated by plasma or by heat as well to activate it and to desorb adsorbents prior to silicoating. Without successful treatment, adsorbents would interfere with the adherence of silicate particles and prevent their close contact with the ionic bonds dangling at the surface.

Due to Fig. 2, the bond strengths reveal stable behavior in the periods under review. As characteristic for adhesively joined systems, their adherence based on silicate/silane layering initially shows a slight decrease in bond strength. After passing through a minimum the bond strength re-increases again. This means that the adherence to the ceramic surface is principally stable against hydrolysis. Even the particularly detrimental storage in boiling water [14] has only a minor adverse effect. Those bond strengths should be compared with the bond strengths without the application of the silicate/silane layer (10.9 MPa, column on the far left).
Moreover, Fig. 2 proves that both treatments (heat and plasma treatments) result in very similar outcomes, revealing identical bond strengths for both treatments when considering the standard deviation. Heat treatment is a low cost procedure since it requires only inexpensive hardware, namely a firing furnace suitable for a temperature of $500{ }^{\circ} \mathrm{C}$ at maximum. A disadvantage is that the samples must be allowed to cool down for about one hour depending on their weight before silicoating becomes possible. Plasma treatment requires more sophisticated hardware; however, after treatment no waiting period must be noticed. The temperature rise due to the energy input of the plasma treatment into the sample is neglectable.

Figure 3 in accordance with Fig. 2 shows that heat and plasma treatments have similar outcomes. However, it should be noticed that those similar results depend on degree and kind of surface contamination! The cleaning effect of heat treatment as compared with plasma treatment may be equal for physisorbed and chemisorbed artefacts adsorbed from the lab environment but not for residuents of a washing procedure (e.g.), as residual surfactants may stick to the ionic bonds at the ceramic surface [27] in such a manner that heat treatment may be able to remove those artefacts but plasma treatment is not efficient! The artefacts still stuck to the ionic bonds, obstructing the bonding from the gas phase of the $\mathrm{SiO}$ molecules needed for effective PVD layering. Note that even heat treatment is sometimes not effective for eliminating certain surface contaminations.

Figure 3 shows that the resorption process taking place out of the lab environment is a very slow process in course of time. Considering the standard deviation, there is no significant difference in bond strength regardless of whether the time elapsed for resorption prior to PVD layering was $30 \mathrm{~min}$ or 7 days. This means PVD layering even after waiting time of $30 \mathrm{~min}$ or 7 days may be efficient.

Figure 3 also reveals that prior to its PVD, layering activation of the surface by heat or plasma treatment results in a considerable increase of bond strength as compared with "activation not done" (column in first position). Without activation, PVD layering is less than half so efficient (10.9 MPa vs. 25.2 MPa and 21.5 MPa, respectively).

Finally, Fig. 2 demonstrates if neither activation nor PVD layering is applied the bond strength is limited to a very low value, in good agreement with results alio loco achieved under comparable test conditions [28]. Also, 
Bergschmidt [29] reported reduced in vitro adhesion between ceramic femur components cemented to saw bones if the retention surfaces of the prostheses have not been treated at all for better bond strengths. Due to this latter investigation, the initial bond strength was about $6 \mathrm{MPa}$, decreasing to a bond strength near zero under the condition of 60-day wet aging and for a cement layer thickness as normally clinically realized.

Nevertheless the low bond strengths of ceramic prostheses to the PMMA cement which have clinically been inserted with a surface "as fired", Bergschmidt et al. [30,31] reported in a follow up study for those prostheses that no aseptic loosening has been observed during a period of 24 months. This could lead to the conclusion that for successful insertion for short or intermediate term, obviously only very low bond strengths between bone cement and prosthesis are required - provided those preliminary positive results endure for a 60-month period (e.g.). Moreover, it must be noticed that this outcome was reached for femoral components which under the aspect of joining technology have very favorable positive form locking because of their clamp like undercut geometry.

For tibial components, the positive form locking is much less favorable. This noticeable difference is impressively reflected by the rate of revision operations induced either by loosening of femor component or by loosening of tibia component. The documentation of the clinical relevancy of that difference in positive locking can be found in a report of the "Geschäftsstelle Qualitätssicherung im Krankenhaus" for the federal states of Germany Baden-Württemberg and Thuringia (e.g., analogous results for other federal states of Germany can be found in the Internet). This comparative quality study ( $\$ 137$ SGBV) revealed that on average tibial parts $40 \%$ more frequently loosen than femoral parts (examples for the year 2012: basic population of patients 1839. 504 patients suffered from loosening of the femoral components and 715 patients suffered from loosening of the tibial components) [11,32-35].

Finally it would be very useful when investigations for ceramic tibial parts would become available complementary to the investigations of Bergschmidt et $a l$. on femoral parts. Note that for the above mentioned follow up study, Bergschmidt et al. [30,31] inserted cemented metallic tibial parts machined out of TiAlV alloy complementary to the ceramic femoral parts.

In order to achieve a compensation for the poor positive locking of tibial parts, cement pockets inserted in their retention surface are discussed. However, it is argued that those cement pockets will result in additional residual stresses in the cement layer partly claiming the bond strength between prosthesis and bone [28]. Contrary to those arguments, post mortem investigations revealed that those pockets may indeed help to improve the retention between the osseous tibial head and the tibial part of the prosthesis [11].

The layer system proposed in the present work can be a feasible alternative to gain additional and more hydrolytically stable bond strength between bone cement and prostheses at the same time, improving the long term prognosis of prostheses in particular in those cases when aseptic loosening is the reason for loss [11]. Note that the adhesive strength between bone cement and an untreated ceramic surface is lost completely after a time of immersion of 60 days in physiological saline solution [36].

\section{Summary and conclusions}

Allergical diseases are very common and widespread. In Germany, nearly one third of the population suffer from allergic complaints. 60 years ago, the corresponding rate was $1 \%-2 \%$. In the last decades, allergies against nickel, cobalt, and chromium have risen at a rate of $20 \%$ [37]. Therefore, the development of prostheses having low rates of abrasion correspondingly being associated by low allergic impact is an important issue [38].

Besides prostheses manufactured out of $\mathrm{CoCrMo}$ alloys, their surface, however, encapsulated by a zirconium nitride layer which shields against the allergic potential of the CoCrMo alloys and at the same time warranting a low abrasion rate, prostheses manufactured out of ceramics may contribute solving the problem of the allergic impact of orthopedic implants.

\section{Acknowledgements}

The authors would like to thank the ISF Welding and Joining Institute of the Technical University of Aachen for measuring the surface energies of polished surfaces of tibial parts of CoCrMo and ZPTA prostheses.

\section{References}

[1] Marx R, Faramarzi RT, Jungwirth F, et al. Silikatbeschichtung zementierter Titanschäfte für die Reduzierung aseptischer Lockerungsraten. Zeitschrift fur 
Orthopadie und Unfallchirurgie 2009, 147: 175-182.

[2] Oonishi H, Aono M, Murata N, et al. Alumina versus polyethylene in total knee arthroplasty. Clin Orthop Relat Res 1992, 282: 95-104.

[3] Oonishi H, Ueno M, Kim SC, et al. Ceramic versus cobalt-chrome femoral components; wear of polyethylene insert in total knee prosthesis. J Arthroplasty 2009, 24 : 374-382.

[4] Otto M. Klassifikation bei Protheseninsuffizienz und Partikelbestimmung. Der Pathologe 2008, 29: 232.

[5] Willmann G. Keramische Pfannen für Hüftendoprothesen. Teil 3: Zum Problem der Osteointegration monolithischer Pfannen. Biomedizinische Technik 1997, 42: 256-263.

[6] KRÜSS. Solids: Values for the surface free energy of solids. Available at http://www.kruss.de/services/education-theory/ substance-data/solids/.

[7] Reisgen U. Private communication. Nov. 20, 2014.

[8] Nevelos J. Surface engineering of prosthetic knee components. Knee 2004, 11: 163-167.

[9] Telle R. Keramik. Berlin: Springer, 2007.

[10] Ihle M, Mai S, Siebert W. Keramik- und Metallköpfe im Dauertest - eine Langzeitanalyse des PE-Abriebs nach 20 Jahren. Orthopädische Praxis 2009, 46: 225-234.

[11] de Uhlenbrock AG, Püschel V, Püschel K, et al. Influence of time in-situ and implant type on fixation strength of cemented tibial trays-A post mortem retrieval analysis. Clin Biomech (Bristol, Avon) 2012, 27: 929-935.

[12] Munz D, Fett T. Ceramics. Mechanical Properties, Failure Behaviour, Materials Selection. Berlin: Springer, 1999.

[13] Musil R, Tiller HJ. Der Kunststoff-Metall-Verbund. Heidelberg: Hüthig, 1989.

[14] Plueddemann EP. Silane Coupling Agents. New York: Plenum, 1982

[15] Kendall K. Adhesion: Molecules and mechanics. Science 1994, 263: 1720-1725.

[16] Information on http://de.wikipedia.org/wiki/Ausheizen.

[17] Kern M, Barloi A, Yang B. Long-term resin bond strength to zirconia ceramic after different surface conditioning. J Dent Res 2008, 87: 1059.

[18] Wirtz DC. Eine neue Beschichtungsmethode für zementierte Femurschaftimplantate zur hydrolysestabilen Optimierung des Metall-Knochenzement-Verbundes. Habilitation dissertation. Aachen (Germany): Wissenschaftsverlag Mainz, 2001.

[19] Edelhoff D, Abuzayeda M, Yildirim M, et al. Adhäsion von Kompositen am hochfesten Strukturkeramiken nach unterschiedlicher Oberflächenbehandlung. DtschZahnärztl Z 2000, 55: 617-623.

[20] Lastumäki TM, Lassila LVJ, Vallittu PK. The semi-interpenetrating polymer network matrix of fiber-reinforced composite and its effect on the surface adhesive properties. J Mater Sci: Mater M 2003, 14: 803-809.

[21] Mannocci F, Sherriff M, Watson TF, et al. Penetration of bonding resins into fibre-reinforced composite posts: A confocal microscopic study. Int Endod J 2005, 38: 46-51.

[22] Habenicht G. Kleben. Grundlagen, Technologien, Anwendungen. Berlin: Springer, 2009.

[23] Erli HJ, Marx R, Paar O, et al. Surface pretreatments for medical application of adhesion. Biomed Eng Online 2003, 2: 15 .
[24] Marx R, Fischer H. Werkstück und Verfahren zum Herstellen und zum Verwerten des Werkstückes. DE-Patent 19937864, EU-Patent 1202 702, US-Patent 6,777,028, Aug. 1999.

[25] Edelhoff D, Weber M, Spiekermann H, et al. PVDBeschichtung für verbesserte Retention glasfaserverstärkter Wurzelkanalstifte. Schweiz Monatsschr Zahnmed 2006, 116: 992-999.

[26] Marx R, Faramarzi R, Oberbach T, et al. PVD-SilikatBeschichtung für die verbesserte Zementhaftung auf Endoprothesen aus ATZ-Dispersionskeramik. Z Orthop Unfall 2012, 150: 40-47.

[27] Hoffmann H, Spindler J. Verfahren in der Beschichtungsund Oberflächentechnik. München: Hanser, 2014

[28] Leyen S, Vetter S, Plank H. Analysis and investigation of the adhesive strength of ceramic and bone cement in knee arthroplasty. In: Bioceramics in Joint Arthroplasty. Lazenne JY, Dietrich M, Eds. Darmstadt: Steinkopf, 2004: 57-59.

[29] Bergschmidt P. Präklinische und klinische Testung einer bikondylären Knieendoprothese mit einer neuartigen keramischen Femurkompenente. Habilitation dissertation. Rostock: Universitätsmedizin, 2013.

[30] Bergschmidt P, Lohmann C, Ganzer D, et al. Knieendoprothetik mit keramischen Femurkomponenten. Der Orthopäde 2011, 40: 224-230.

[31] Bergschmidt P, Bader R, Ganzer D, et al. Ceramic femoral components in total knee arthroplasty-Two year follow-up results of an international prospective multi-centre study. Open Orthop J 2012, 6: 172-178.

[32] Information on http://www.geqik.de/fileadmin/Archiv/ 2011/Jahresauswertungen/m17n7_gesamt_2011.pdf.

[33] Information on http://www.geqik.de/fileadmin/Archiv/ 2012/Jahresauswertungen/Gesamt_17_7_2012.pdf.

[34] Information on http://www.laek-thueringen.de/wcms/ DocsID/A91383C5DE9F95C0C1257A5B00423B70/\$file/ 2011_17n7_Knie-Totalendoprothesen-Wechsel.pdf.

[35] Information on http://www.laek-thueringen.de/wcms/ DocsID/F39E635AF3E63103C1257B8D0035EABD/\$file /2012 17n7-Knie-Endoprothesenwechsel\%20und\%20-Ko mponentenwechsel.pdf.

[36] Vetter St. Analysis and valuation of the adhesive strength of ceramic and bone cement in knee arthroplasty. Diploma Thesis. Denkendorf (Germany): Institute of Textile Technology and Process Engineering, 2003.

[37] Thomas P, Schuh A, Ring J, et al. Orthopädischchirurgische Implantate und Allergien. Der Orthopäde 2008, 37: 75-88.

[38] Murray MGS, Facchini A, Sicking R, et al. Development of an advanced ceramic/titanium alloy knee joint. Bioceramics 1999, 12: 67-70.

Open Access The articles published in this journal are distributed under the terms of the Creative Commons Attribution 4.0 International License (http://creativecommons.org/licenses/ by/4.0/), which permits unrestricted use, distribution, and reproduction in any medium, provided you give appropriate credit to the original author(s) and the source, provide a link to the Creative Commons license, and indicate if changes were made. 